\title{
28
}

\section{Traversing Ethical Imperatives: Learning from Stories from the Field}

\author{
Gareth J. Treharne, Phindezwa Mnyaka, Jacqueline Marx, \\ and Catriona Ida Macleod
}

What lessons stand out across the four sections of this handbook? How do the rich, storied examples of research shared in each chapter take critical researchers forward in thinking through the complexities of conducting ethical research? In this conclusion, we home in on some of the implications of the grounded exercise in which we engage throughout this handbook.

The stories from the field shared in each chapter form a series of critical interventions that invite discussion about the status quo and the future of research ethics as applied to critical research. Stories about critical research have the effect of creating an opportunity to reflect on ethically important moments in the unfolding research processes. Rarely is there an opportunity for detailed ethical reflection in empirical research articles, and as Brinkmann and Kvale (2017) note, 'In today's handbooks and textbooks of psychology and other social sciences, the ethics chapter is often a small and marginal chapter, if included at all' (p. 260). That is not to say that there is not a vast

\footnotetext{
G. J. Treharne $(\bowtie)$

University of Otago, Dunedin, New Zealand

e-mail: gtreharne@psy.otago.ac.nz
}

P. Mnyaka

Department of History, University of the Western Cape, Bellville, South Africa e-mail:pmnyaka@uwc.ac.za

J. Marx $\bullet$ C. I. Macleod

Critical Studies in Sexualities and Reproduction, Department of Psychology,

Rhodes University, Grahamstown, South Africa

e-mail: jacqui.marx@ru.ac.za; c.macleod@ru.ac.za 
and growing literature on research ethics applied to critical methods; indeed, this literature is drawn upon throughout this handbook, but stories of ethical challenges and conundrums benefit researchers by providing a detailed consideration of how we might work through such dilemmas.

The four sections of the handbook focus on the challenges that surround particular ethical imperatives relating to: (1) systems within which research is conducted, (2) boundaries to research relationships, (3) anonymity of participants and organisations, and (4) the relative power of participants and researchers. Each of these sections is preceded by a framing introduction in which the key issues highlighted in the chapters are foregrounded and discussed. We do not reiterate these issues in this chapter, but rather speak to overarching concerns that cut across the four sections.

Many of the challenges exemplified across the whole handbook are the result of the increasing governance imposed by the research ethics assemblage and from colonisation of research ethics by imperatives arising from biomedical research, which are, in many instances, incompatible with the aims and methods of critical health and social research. We have framed the handbook within the notion of traversing ethical imperatives. This works at two levels: firstly, critical researchers are frequently required to traverse ethical imperatives at particular moments during research, as exemplified by chapter authors; and secondly, critical researchers as scholars using a diverse conglomeration of epistemologies and methodologies have a collective need to traverse ethical imperatives by compiling ethical processes that fit the challenges faced in critical research. The primary function of the handbook is as a resource for researchers who are applying critical methods and seeking guidance. The primary message of the handbook is that ethical guidance cannot be reduced to a closed set of principles; instead, the chapters provide nuanced considerations to inspire researchers to be creative and transparent when facing their own ethical challenges. This chapter covers four overarching concerns addressed throughout the handbook relating to: (1) learning how to navigate process ethics in critical research, (2) constructions of vulnerable subjects in critical research, (3) seeking social justice through participation in critical research, and (4) reimagining ethics review for critical research.

\section{An Agenda for Learning About Ethical Conduct in Critical Research}

Critical researchers apply a range of methodological and analytical skills, as featured throughout this handbook. Researchers learn about research methods and ethical processes in many ways. We learn about research and 
ethics by being schooled and socialised into our particular cultural understandings. We learn about research ethics during tertiary education, but this is often limited to hearing about the implicit norms of mainstream research methods. There is, of course, no requirement for critical researchers to have undergraduate or postgraduate qualifications, but for critical researchers with tertiary qualifications in social sciences or health sciences, learning about critical research has often been secondary to being taught about positivist epistemologies and associated research methods (Hale, Treharne, \& Kitas, 2007; Lyons \& Chamberlain, 2006, 2017; Murray, 2014b). We also learn as we go about our own critical research often by a process of trial and error. We learn through stories shared by other critical researchers who analyse their experiences and make recommendations as do authors across all chapters of the handbook. The burgeoning bureaucracy of research ethics can include training requirements. Below, we outline some of the contingencies involved in learning about the ethical conduct of critical research in terms of: induction into the field; communities of practice; and researcher reflexivity.

\section{Induction into the Field}

One of the entry points into learning about a particular field is to gain insights into a lexicon of terms, their meanings, uses, and the debates to which they allow access. Across this handbook, authors use a diversity of terms relating to research ethics that readers can apply when planning and conducting research; when supervising, examining, or reviewing research; when teaching research methods and ethical practice; and when musing on, debating, or publishing research. Within this lexicon of terms, there is a broad distinction. On the one hand is the hegemonic neutral-normative model of procedural ethics that gets transcribed into research protocols and presented to ethics committees as a tool of risk avoidance. On the other hand, there is a more flexible normcritical model of ethics that is required in the field and is referred to variously as situated or situational ethics, process ethics, micro-ethics, everyday ethics, ethical mindfulness, or applying an ethical sense or ethical principles (see, e.g., Haggerty, 2004; Hammersley, 2015).

The processes through which researchers are formally inducted into an ethical sense and ethical ways of researching merit attention. Many of the authors featured in this handbook highlight how ill-prepared they felt to face the challenges they encountered once in the field. Brinkmann and Kvale (2017) note that ' $[\mathrm{h}]$ istorically, what we call social science emerged from moral philosophy, and the student of social science had to acquire moral dispositions as part of 
the curriculum' (p. 260). With the current influence of natural science and positivism in the social sciences, a key concern is the extent to which ethics, as a contextual, ideological, and moral process, is integrated into the training of critical researchers or in teaching content that draws on the findings of critical research. Ethics is often considered only prior to entry into the field, and likewise ethics is frequently viewed as an added extra in teaching about research.

Realist literature reviews of 'ethics training interventions' demonstrate that researchers can learn to follow ethical approval processes or apply specific ethical principles (Steele et al., 2016), including application to communitybased research (Quigley et al., 2016). But these training interventions do not exist outside particular institutional goals and national requirements for compliance of researcher training. Prescribed research ethics training may not, however, fit with methods of critical research and may not teach critical researchers much other than how to manage ethics review systems that were, for the most part, not formed to account for the methods that critical research involves nor the specific ethical challenges that critical researchers can face (see in particular Carter, Chew, \& Sutton, Section 1). Inserting critical research principles into ethics training means understanding these power relations and helping researchers think through dealing with the need for compliance.

In addition, realist models of learning contribute to the construction of a lay/professional divide between participants and researchers, particularly in relation to ethical principles. For example, van den Hoonaard (2011) highlighted how "beneficence" implies paternalism, that "only medical researchers would know what's good for you"' (p. 116). Even the word 'beneficence' is paternalistic in its complexity. Similarly, formal induction into ethical conduct of critical research should highlight the importance of ethical processes as negotiated, ongoing, and respectful.

\section{Communities of Practice}

Many authors throughout the handbook describe having to seek ethics clearance or ethics approval but found that the bureaucratic processes cannot account for critical research because it does not fit into a positivist and/or biomedical frame of research. Critical research is often stalled and, in the worst cases, a project may never proceed (e.g., Marx \& Macleod, Section 3). As discussed in depth later in this chapter, the aim of this handbook is not to call for an imminent and radical rejection of ethics clearance procedures. What becomes clear across the chapters in this handbook, however, is that the 
seeking of ethics approval is often encountered as a hurdle instead of it providing critical researchers with a much-needed opportunity to learn from ethical advice given by a person with experience. What this means is that we are not seeing formal institutional 'communities of practice' that can support critical researchers in learning about research ethics. Arguably, this should be a central function of ethics committees, but this handbook outlines ways in which critical researchers are misunderstood by ethics committees and have to defend themselves during ethics review processes rather than their being supported by a community of practice.

There are, however, networks of researchers outside and across academic institutions that support researchers and radically question the directions in which ethics bureaucracy is being taken. For example, the Ethics Rupture network was formed at their 2012 conference which initiated several academic volumes (Iphofen, 2017; van den Hoonaard \& Hamilton, 2016). Likewise, many academic societies such as the International Society of Critical Health Psychology (ISCHP) are dedicated to the development of critical perspectives on research, including research ethics, and it was at the 2015 ISCHP conference in Grahamstown that this handbook was conceived. Likewise, the field of bioethics includes many academic societies and has a long history of contributions to critical scholarship (see, e.g., Reubi, 2010; Twine, 2005).

Critical researchers frequently find that they are required to learn about and defend the epistemology of their approach because of the inequitable interrogation of critical methodologies as is highlighted in many of the chapters featured in this handbook. While this may be difficult, a benefit of this inequitable pressure is the mutual learning that goes into positioning critical research in the wider constellation of epistemologies. In response to this, it is increasingly necessary for critical researchers to learn collectively to resist ceremonial bureaucracy such as irrelevant training and irrelevant questions on ethics applications and reporting forms (Carter et al., Section 1). This resistance also entails developing a sense of which ethical issues in critical research can be expected, planned for, and detailed in ethics applications. Critical researchers also have a role to play in collectively resisting the coopting of criticality, particularly when the notion of 'critical' is employed to mean doing better mainstream research (Ogden, 2012).

While this handbook was enabled by the community of practice of ISCHP (established at a conference in 1999), the handbook itself represents a community of practice. Through sharing their stories of struggles, challenges, reflections, conclusions, and actions, the authors create a community of practice with which researchers may engage in relation to their own critical research encounters to develop strategies to deal with restrictive ethics review processes. 


\section{Researcher Reflexivity}

One of the greatest challenges for all researchers, and critical researchers in particular, is 'how to learn ethical research behaviour' (Brinkmann \& Kvale, 2017 , p. 260). The notion that to be ethical is embedded in an individual's 'behaviour' requires deconstruction. Speaking of research participants, van den Hoonaard (2011) argued: 'It is an important philosophical premise to see individual human beings as primarily 'autonomous' entities. Such a premise conjures the view of a human being without relation to others' (p. 61). The same should be argued of researchers: there is both a need to recognise autonomy and to recognise that ethical considerations do not occur in a social vacuum. For example, Whiteman (2017) raised the concern that critical analysis of research ethics continues to be individualising and interiorising, both of which are critiques that critical researchers are more used to making of mainstream research than of our own analyses. But, like the chapters in this handbook, analyses of research ethics can be reoriented to give consideration of institutionalised interrogation 'to avoid falling back on the autonomy of the person whilst maintaining the openness of ethical negotiation' (Whiteman, 2017, pp. 14-15).

Nevertheless, reflexivity in conducting research is an important aspect of researcher learning in ethics. One of the guiding features of criticality is a constant return to the self-criticism of one's praxis and one's field (Lyons \& Chamberlain, 2006, 2017; Murray, 2014a; Murray \& Chamberlain, 2014). The chapters in this handbook apply this self-criticism, sometimes drawing effectively on the notion of confessional reflexivity to demonstrate moments of learning (e.g., Carter et al., Section 1; Harvey, Section 2; Naidu, Section 3; Mayeza, Section 4).

There are several other facets of learning about research ethics that are evident across the chapters. The ethics of insider/outsider positioning (Wilkinson \& Kitzinger, 2013) are brought to attention in the work by Harvey (Section 2) on being a researcher with a visible disability who interviewed mothers whose children have a disability, which resulted in assumptions of shared understanding and a sense of being researched back. Hay-Smith et al. (Section 2) also address the insider/outsider positioning of health professionals who conduct research and the ways the duty of care and relationality extend to other critical researchers. Many ethical issues of critical research are unpredictable and require nuanced learning about very specific applications of research and processes (Edelman, Section 1; Feltham-King et al., Section 1; Stewart, Section 4). The chapters throughout the handbook also draw attention to various stages of fieldwork. Entering the field requires learning 
how to develop relationships that are authentic and mutual whilst avoiding exploitation, whether intentional or unintentional, and maintaining professional boundaries. Being in the field requires learning how to recognise and work through ethical dilemmas. And exiting the field requires learning how to share feedback on findings, how to successfully finish research relationships, or how to remain in the field forever in some ways when there is no clear distinction between the fieldwork and the researcher's daily life.

\section{Conceptualising Vulnerabilities and Harms}

In this handbook a range of what could be considered vulnerable participants formed part of the stories of research: people living with HIV/AIDS in environments in which the HIV stigma is high; pregnant and mothering teenagers accessing services in under-resourced settings; survivors of sexual violence; psychotherapy clients; people with disabilities; mothers raising children with visible disabilities; women with problematic drug use; participants with a history of criminal offence; and dogs who are seen as pets or as being owned by humans. As 'vulnerabilities' and 'harms' are so central in the consideration of research ethics, it is clearly important for critical researchers to ask questions about taken-for-granted assumptions underpinning these notions. What is at stake in labelling a group of people as vulnerable? Who makes the decision, and on what basis? And in relation to what kind of social or personal benefit or well-being are 'harms' understood and assessed? How are the remedial steps defined in relation to the ways in which harms are conceptualised? Under what conditions are harms recognised or erased? These kinds of reflections are essential in terms of the manner in which critical researchers engage with the signifiers 'vulnerability' and 'harm' in their research protocols and research reports.

Researchers are often required to demonstrate that they have put protective mechanisms in place to ensure that the research does not compound vulnerability or, where it does, that there are remedial steps in place to manage the increased risk. In addition, in those situations in which vulnerabilities mean that autonomous decision-making is circumscribed - for example, in the case of refugees seeking asylum or other legal status determinations (Pittaway, Bartolomei, \& Hugman, 2010)—researchers are required to put in place additional processes of confirming or affirming consent.

Given that ethics committees emerged from a history of multiple abuses in research that involved human beings subjected to unethical research, it is understandable that vulnerabilities and harms are foundational principles 
underpinning research ethics. In order to justify the conduct of their research, researchers are tasked with outlining the benefits of the study and to answer questions regarding the balancing of the harms and benefits so that ethics committees can determine whether the benefits outweigh the harms or vice versa. Problems arise, however, when benefits are viewed at an individual level only. Questions on ethics clearance applications regarding direct and indirect benefits are not neutral. Working in the shadows of bioethics means having to navigate the special status afforded to direct benefits that privilege individuals participating in the study rather than communities, social groups, or society at large, or where these broader benefits are considered secondarily to vulnerabilities and harms. When research committees foreground vulnerabilities and start to fetishise the possibilities of, for example, embarrassment or discomfort, then the balancing of benefits and vulnerabilities is out of kilter. Furthermore, when benefits are not cast within a framework of social justice, then these may be reduced to mundane questions such as whether participants receive a gift or reimbursement for participating in the research. A central question that critical researchers and ethics committees need to ask is: where research can be shown clearly to be of social benefit or to contribute to social justice (e.g., highlighting multiple abuses), what level of individual harm (e.g., to people perpetrating the abuses) can be tolerated in the conduct of critical research?

Too frequently, vulnerability is taken to mean individual risk on account of attributes internal to the participant. As disability scholars and others have pointed out, however, vulnerability is also a function of the environment within which we live. Barriers to accessing buildings, for example, make people with physical impairments vulnerable (see Harvey, Section 2; Rice, LaMarre, \& Mykitiuk, Section 3). A shift from thinking about vulnerability as an internal quality to understanding vulnerability as always already socially constructed and maintained requires researchers to understand vulnerability as multiply relational and located at the intersection of various power relations. In this view, a 'vulnerable person' becomes 'a person with vulnerabilities' or even 'a person positioned as vulnerable' or 'a person made vulnerable'. Vulnerability, thus, is seen as a socially located praxis rather than a personal characteristic, and not as something that defines particular individuals at all times and places. How researchers view and approach their participants matters, not only in terms of the validity of the study, but also in relation to what potential outcomes the interactions have. Particular interactions, mostly paternalistic, are enabled by a view of vulnerability as an inevitable component of participants' lives, or alternatively as a material and fixed reality. Different interactions are possible when vulnerability is viewed as firmly located in multiple, intersecting power relations and where agency, even when 
limited, is acknowledged and understood as located in contexts that either enable or hinder it.

One ironic possible consequence of a conventional approach to understanding vulnerabilities is that researchers may encounter participants through a rigid and potentially debilitating frame. This kind of framing may be seen as necessary in order to construe those features within the category as 'worthy' of research. That is to say, researchers may unwittingly find themselves problematising participants, rendering them vulnerable in discursive terms, in order to justify funding or approvals for the research or to facilitate recruitment (e.g., Feltham-King et al., Section 1).

\section{The Politics of Vulnerabilities and Harms}

While harms are generally understood in relation to actions undertaken (in this case research), lack of action may also result in harm. When researchers avoid undertaking particular kinds of research or research with particular participants, it tends to be because: the participants in question are viewed as 'too vulnerable'; the bureaucratic hurdles of ethics committees are too onerous (Richardson \& McMullan, 2007); or researchers fear that ethics committees will fail to understand the proposed critical research method (Marx \& Macleod, Section 3). The result is that harms may accrue owing to lack of action when research does not proceed (Juritzen, Grimen, \& Heggen, 2011). As Rucell (Section 3) so poignantly asserts, a range of institutional abuses may go unchallenged as a result of the notions of 'vulnerability'. The question of 'harms' may be put to use to prevent critical research being undertaken in these spaces.

In addition, the very act of protecting participants through foregoing sensitive research may mute or deny the expressions of marginalised people (McKenzie-Mohr \& Lafrance, 2011). As Edelman (Section 1) points out, particular participants may be prevented from being part of a research project on the basis of their 'vulnerabilities'. Edelman argues that in some of these cases, neoliberal notions of harms take precedence over social justice aims, which would include the provision of spaces within which marginalised voices may be heard, and the recognition of the agency of the oppressed in deciding on participation despite possible individual 'harms'.

Children or minors present a particular case in point. Most ethics application processes will inevitably mark child participants as vulnerable no matter how benign the research question or data collection method. Purely on the basis of age, children are deemed to require protection. The result of this is 
that 'researchers have tended to undertake research on the least vulnerable/ most adult-like children' (Carter, 2009, p. 858). These 'tick-box' responses to child participants overlook the increasing trend towards child rights and participation, and the fact that children are not a homogenous group. Mayeza (Section 4) highlights, for example, how gender intersected with age in the construction of vulnerability in his research. Ashdown et al. (Section 3) demonstrated how children can take on active roles in research through methods like photo-elicitation; in this instance, the children became responsible for gathering consent from people who appeared in their photographs as part of their acknowledged contribution to the research.

If, as discussed in the main introduction of this handbook, critical research is about power relations, then questions of empowerment, emancipation, and liberatory practices need to be considered alongside an ethic of 'do no harm' in research. Authors of chapters in the handbook have explicitly tackled the complex questions of what it means to engage with research that speaks to undoing or undermining oppressive practices and structures. In addition, Swartz (2011) argues that ethical strategies should explicitly address vulnerability and emancipation in practice. Smith's (2008) notion of 'responsible advocacy' captures this imperative, the aim of which is 'to avoid coercion and exploitation of vulnerable individuals and groups in research, increase validity and reliability, and avoid pre-emptive exclusion of such groups in the research design' (p. 248).

Vulnerabilities can, of course, be created or exacerbated by research. In Section 3, for example, authors grapple with the question of anonymity, confidentiality, and voice. Harms may accrue to participants if anonymity is not maintained in research under certain circumstances. These harms need to be balanced, however, with the harms of lack of voice, as well as the potential harms of unrealistic promises of anonymity and confidentiality. Thus, while critical researchers need to question how notions of 'vulnerabilities' and 'harms' are understood and deployed in research, they equally need to inspect very thoroughly the procedures they implement, the interactions that they have with participants, and how the outcomes of the research may impact not only on individuals, but also on their families and communities.

\section{The Vulnerabilities of Researchers}

Vulnerability extends not only to participants but also to researchers who may experience their encounters in the field as distressing, especially in circumstances in which there is in-depth engagement in the field (e.g., Akhurst et al., 
Section 2). During in-depth encounters, such as interviews about personal and sensitive issues, researchers may select to reveal, or want to reveal, their own experiences of such issues (e.g., Edelman, Section 1). Whilst sensitive encounters and revelations may be beneficial to the research, they also may be distressing for the researcher. Generally, researchers can attempt to overcome such distressing effects through engaging in debriefing sessions, self-care, counselling, and reflexive writing. Unfortunately, these kinds of activities are rarely factored into research grants or support structures, despite the fact that:

[r] esearch institutions have a duty of care to ensure that researchers are not in undue danger, and this includes access to counselling support when it is known to be likely that they have spent time interviewing people about [...] traumatic stories (Pittaway et al., 2010, p. 235).

If we see vulnerability as relational, then the vulnerable positioning of researchers in the research encounter can act as a key focus of analysis and insight. What do the vulnerabilities experienced by the researcher suggest about the interactional space and power relations set up in this research? These kinds of questions have generally been discussed under the rubric of reflexivity in critical research. Reflexivity refers in this context to deep reflection not only on the social categories within which the researcher is located vis-à-vis the participants, but also to the unfolding dynamics that take place in research spaces. Researchers have argued that this kind of reflexivity should not appear as a brief confession but should be integrated throughout the report, including in the analysis (Etherington, 2007).

This connection, between researcher subject positions in the research encounter and the interpretation of the data, is what lifts discussions on reflexivity from a methodological concern to an ethical one. In reflecting on the vulnerabilities invoked in the self in the research encounter, the researcher is able not only to encapsulate power relations in situ, but also to be productive in exposing the self and participants in particular ways. As argued by Etherington (2007):

Reflexivity, although enabling the conduct of ethical relational research, also requires researchers to come from behind the protective barriers of objectivity and invite others to join with us in our learning about being a researcher as well as remaining human in our research relationships. (p. 599)

In other words, in writing up the results of the research in reflexive ways, the researcher joins the participants in the potential learning that can arise from the sharing of sensitive and intimate details of their lives. 


\section{Social Justice Through Participation}

If the public circulation and acknowledgement of gross violence in research in the twentieth century were foundational in concretising codes of ethical research conduct, in the twenty-first century, researchers are compelled to take into serious consideration large-scale inequalities as well as insidious circuits of power in which research may take place. What emerges strongly in a number of chapters throughout this handbook is the centrality of social justice as a paradigm through which ethical dilemmas are negotiated.

Institutions of research are far from neutral in the seemingly divergent spaces of administrative bureaucratic committees and critically driven theoretical research as well as the spaces in between. The elevated ground where members of universities were once located is increasingly shaky. Researchers are being called upon to locate their research in local contexts and realities, to produce applied research that can be used by communities, and to acknowledge their entanglement with fractured ideological, political, and social power relations.

Not by coincidence then, in different formulations, the chapters in this handbook attend to the question of social justice as a foundation that features in the doing of critical research and ethics. Research communities have often been accused of being extractive, generating knowledge of benefit primarily to the researcher, and reinforcing particular power relations. For example, critical disability researchers remain cognisant of the way the bodies of people with disabilities have been used in instrumentalist ways by researchers resulting in further reinforcing ableism (see, e.g., Rice et al., Section 3). Intellectual work is deeply embedded in, indeed constituted by, such relationships of power. There is therefore the suggestion that research relationships that build trust and reciprocity should be taken seriously in order to re-think the model of research as a bracketed and isolated act or an event with an ending. Chapters in the handbook refer to the importance of building relationships in varying contexts. Transdisciplinary and participatory research intends to minimise that distance by actively involving participants who identify what is felt to be important enough to be addressed (see, e.g., Cockburn \& Cundill, Section 1).

Taking reciprocal relationships seriously means acknowledging the systems in which all stakeholders are embedded, marked as they are, in legacies of inequality. For scholars committed to advocacy and activist work, traversing spaces outside formal institutions is essential. Participatory action is often an important component of activist-driven research. Having 
members of communities (however defined) as partners in deciding on research questions, formulating how data will be collected and what methodologies are used, collecting and analysing data, and deciding on dissemination is a process that attempts (even as it fails) to undermine particular power relations, depending on the research question.

Guta, Nixon, and Wilson (2013) ask whether what they call ethics creep (the dominance of the formal ethics review assemblage) has become a moral panic that may restrict the uptake of community-based models of ethics review which would limit engagement with participatory methods. In other words, the imbrication of ethics review processes as the sole or most important aspect of assessments of the ethical conduct of research may serve to mask the lack of ethics in failing to engage in community-based participatory approaches.

Nevertheless, the ethics of critical research requires that researchers who do deploy processes that create reciprocal and respectful relationships must simultaneously be cognisant of the potential for these very processes to reinscribe particular power relations (Cornwall, 2003). Cooke and Kothari (2001) draw attention to these potential difficulties in their book entitled Participation: The new tyranny? They argue that people in marginalised positions may be subtly coerced, in the name of empowerment, into activities and decisions for which they are ill-prepared and from which they gain little. The 'tyranny of the group' emerges when participatory approaches fail to take account of complex power relations and inequalities within communities. As such, they may reinforce or strengthen already existing relations of power in these communities. Cornwall and Brock (2005) argue that 'participation' has become a buzzword that robs participatory research of its potency. Politicised versions of participatory research cognisant of the complexities involved in conducting ethically responsive research that contributes to social justice are increasingly called for (Hickey \& Mohan, 2004).

In addition, epistemological access cannot be overlooked; access to knowledge production resources reinforce traditional Western institutions as bastions of knowledge. This can create conditions of 'trusteeship' if it is the researcher who is seen as having 'granted' a space for participation. Yet, even when researchers clearly aim to do no more than generate knowledge, this does not prevent their positioning from being capable of effecting social and economic change, compelling them to face growing forms of disenfranchisement that exist alongside growing knowledge about the world. This raises many questions about the future of ethics review as applied to critical research. 


\section{Reimagining Ethics Review}

Throughout this handbook, authors have illustrated how certain conventions in the interpretation and application of standard ethics principles have undermined the ethical conduct of critical research. Chapter authors have called for ethics review processes that are more responsive to the specificities of different types of research, to the fluid and unpredictable nature of flexible methodologies, and to the contextual power relations within which the research is conducted. In the light of the critiques and narratives of ethical conundrums as they played themselves out in the deliberations and decisions of ethics committees, in unanticipated but ethically important moments in the field, and in those often lonely spaces in which we sit down to write this all up, it is pertinent to ask: what does the future hold for ethics review of critical research?

As intimated by the stories from the field shared in the handbook, there are multiple complexities associated with conducting critical social and health research, and potential solutions to ethical conundrums in critical research must be nuanced and responsive to the various critiques these encounters occasion. At the same time, these responses cannot become overly convoluted. They must be honed to speak directly to key issues specific to critical social and health research and the context in which this research is undertaken. In the opening introduction chapter we suggested ethics review processes that are informed by basic ethics principles must be responsive to situated and relational dynamics. Adopting a critical and pragmatic approach has implications for how ethics review of critical social and health research is conducted. This raises a number of questions addressed in this section which members of ethics committees as well as researchers need to ask themselves: How can critical research be better accommodated in the ethics review process? How might the ethics review forms that researchers have to complete be fashioned to encourage both principlist ${ }^{1}$ and contextual ethics responses? How might ethics committees provide support to researchers who attempt to navigate the complexities of conducting ethical critical research? How might ethics committees accommodate participatory research that requires researchers to engage with communities prior to formulating research questions and methods?

\section{Accommodating Critical Research in the Ethics Review Process}

It is well established that medical experts have been over-represented on research ethics committees (de Vries \& Forsberg, 2002). In recent years, growing 
concerns about litigation have resulted in a parallel growth in research ethics committee members with legal training (de Ville \& Hassler, 2001). It is also established that even when ethics committees are not dominated by members from medical or legal professions, they still tend to be unfamiliar with the aims and methods of critical research and are inclined inappropriately to apply ethics principles (Gallant \& Bliss, 2006; Louw \& Delport, 2006). That said, recent research findings indicate that there is a growing awareness among members of ethics committees of the need to be accommodating of emergent and unconventional methodologies (Guta et al., 2013).

Concern about the training and competencies of ethics committee members is not new (Israel \& Hay, 2006), but has been brought to the fore in the context of the review of critical research where a cursory introduction to bioethics is clearly inadequate to the task. Critical researchers have been quick to critique ethics committees, believing that 'their work is being constrained and distorted by regulators of ethical practice who do not necessarily understand social science research' (Israel \& Hay, 2006, p. 1). Curiously, however, critical researchers have made limited contributions to challenging the composition of research ethics committees or in lobbying for the greater involvement of critical researchers, even though our involvement could help to shape new approaches in ethics review.

Many countries now have national guidelines regarding the composition of ethics committees to ensure diversity in terms of gender, ethnicity, ability, and the inclusion of community members. This is to ensure that reviewers of proposed research are not limited to individuals socially and culturally removed from the communities or groups being researched, but these guidelines only set out the minimum requirements and certainly do not foreclose on opportunities to include members representing a broad range of research interests. The findings of recent research indicate that ethics committees experience high workloads (Caligiuri et al., 2017; Guta et al., 2013; Kotsis \& Chung, 2014) so the involvement of a greater number of critical researchers is likely to be appreciated. With a greater representation of critical researchers on ethics committees, some of the common pitfalls in the review of critical research may be averted.

Some universities are experimenting with a system of devolved ethics committees, for example, Queen's University in Northern Ireland, Rhodes University in South Africa, and University of Waikato in Aotearoa/New Zealand. In these instances a central research ethics committee provides secondary support to school- or faculty-level committees to ensure the promotion, review, and monitoring of ethical practice in research (see Queen's University Belfast, 2017; Rhodes University, 2017; University of Waikato, 
2017). This often includes facilitating university-wide conversations to support the development of ethics committee members and researchers and is a form of professional development around ethics review and responsiveness to ethical concerns. As the members of school- or faculty-level ethics committees are likely to be familiar with the methodologies under review, there is a greater opportunity for researchers and reviewers to engage in appropriate dialogue about ethics issues rather than merely aiming to achieve tick-box approval. If frustrations with inflexible, unresponsive, and slow ethics review processes are at least partly as a result of the centralisation of ethics review (Tolich et al., 2016), then the outcomes of experimentation in devolved ethics committees are going to be interesting to observe over the coming decades.

Regarding the ethical responsibilities of ethics reviewers and researchers, Bond (2012) argues that, while these responsibilities can be antagonistic, this need not be the case if reviewers understand their role as being in support of researchers in being ethical. In addition to time, effective ethical engagement in the development of a research protocol requires significant investment of personal values, energy and agency by the researcher which can be supported or undermined by the research process' (Bond, 2012, p. 108). The literature on ethics review suggests that these processes most often occur behind closed doors (Ashcroft \& Pfeffer, 2001; Stark, 2012). And as few researchers have gained access to the inner workings of ethics committees, researchers are often in the dark as to precisely what is required of ethics committee members (Fitzgerald, Phillips, \& Yule, 2006; see van den Hoonaard, 2011, for exceptions).

Tolich et al. (2016) argue that researchers become better aware of the process of ethics when they are invited to attend the ethics committee meetings at which their proposed research will be discussed. By doing this, ethics committee deliberations and decisions become subject to external scrutiny. If the attendance of researchers at ethics committee meetings is used as an opportunity to engage researchers in the constructive dialogue of the ethics issues occasioned by their proposed research, then that discussion might have a positive impact on the review outcome as initial questions or concerns can shift as a result of new information about the research that emerges during discussion. The input of critical researchers in ethics review discussions may also offer rich learning opportunities for both researchers and ethics committee members as debate helps to develop understandings of the ethics issues under discussion. In fact, it is for these reasons that increased availability of research committee members for consultation outside formal ethics committee meetings has been shown to have a positive impact on review outcomes (Guta, Nixon, Gahagan, \& Fielden, 2012; Stewart-Withers, 2016; Tolich et al., 2016). 
Related to the issue of evaluating the benefits of critical research, there is a need for critical researchers to think critically about claims regarding the impact of research that is only accessible to others in our echo chamber, for example, because of the language we use and/or where we choose to publish. Critically evaluating the ethics of, for example, 'research tourism' (Mistry, Berardi, \& Simpson, 2009) would increase the responsiveness of the ethics review process to concerns related to critical research; however, it would be naïve to assume that methodological responsiveness would necessarily make the ethics review process easier to navigate because more pertinent questions are sometimes also more difficult to answer.

\section{Encouraging Both Principlist and Contextual Ethics Responses and Support}

A key message of many of the chapters in this handbook is that ethics committees need to be prepared to acknowledge that some ethics principles should be interpreted in relation to the specificities of the research context. How do ethics committees navigate conflicts in particular principles that may be foregrounded in critical research as when harm to individual participants may accrue in research that aims to contribute to social justice? Do committee members simply revert to traditional interpretations of ethics principles, or are they able to accommodate interpretations of ethics principles informed by epistemologies applied in critical research? There are no straightforward answers to these kinds of questions, but ethics committees are perhaps the ideal location for the deliberation of these very issues.

How do ethics committees navigate the difference between what is legal and what is ethical? Legal and ethical concerns about research often overlap, but typically the impetus behind these concerns is primarily to protect universities rather than individual participants, communities, researchers, or ethics committee members. For example, confidentiality and respect for privacy are ethical imperatives (see Section 3), but they are also constitutionally protected rights in many countries, and failure to uphold confidentiality or respect for privacy can be punishable under law and/or under the regulatory powers of professional practice bodies. In contrast, legal and ethical questions are also raised when researchers are made privy to information about crimes that have been committed or the intention of individuals to harm themselves or another; should such information be considered confidential, or might failure to report such information be considered unethical, or even aiding and abetting under some circumstances? For example, Marzano (Section 4) and 
van den Hoonaard (Section 4 and 2011) discuss research on legally complex issues such as trade in human organs. The question then becomes whether ethics committees and institutions are willing to stand by researchers who are able to make a good case for conducting ethical research that contributes to social justice but which raises legal concerns.

A strategy that has shown promise in terms of making the ethics review process more responsive to the types of research undertaken by critical researchers is for ethics committees to facilitate proportional ethical review. This generally involves tying 'the amount of paperwork, the rigour of the review, and the processing time to a smart assessment of the risks and ethical issues associated with the proposed work' (Allen, 2008, p. 112). There is no reason why this should not include tailoring which questions are posed and the way in which they are posed so as to be responsive to the kinds of research being proposed. This approach is already applied by some ethics committees but usually works on the presumption that researchers are able to choose adequately from tick-boxes describing a range of possible methods. This does not mean that very careful consideration is not required in assessing both the direct and indirect benefits of critical research (see, e.g., Carter et al., Section 1). It is often the case that critical researchers experience 'a real sense of impotence and inadequacy at not being able to do much, if anything, of immediate material benefit' (Cloke, Cooke, Cursons, Milbourne, \& Widdowfield, 2000, p. 139) for participants in vulnerable or precarious circumstances. In these instances we tend to reason that our research includes the prospect of improving the quality of life of the broader community or social group from which our research participants are drawn. While this is sometimes the case, however, it is certainly not guaranteed.

Formative feedback received during researcher consultations with ethics committee members prior to the submission of their ethics protocols for review has a positive impact on both the experience of the review process and the outcome of the review process (de Jong, van Zwieten, \& Willems, 2013; Hedgecoe, 2012; Tolich et al., 2016). The availability of ethics committee members to engage with researchers can be constrained by their workload (Allen, 2008; O'Neill, 2010; Tolich et al., 2016). Comparing ethics review structures and processes across five universities in Aotearoa/New Zealand, Tolich et al. (2016) argue that the volume of ethics applications requiring ethics review in some universities is preventing them from implementing the open-door approach adopted by others. Consequently, it appears that institutional support for ethics committees is required in order to provide the sort of assistance that researchers need in order to navigate successfully the ethics review processes. 
When institutional support is provided, then previously 'dysfunctional' ethics committees can become responsive. For example, Griffith University in Australia implemented an intervention to address long-standing frustrations with the ethics review process (Allen, 2008). One aspect of the intervention involved establishing a research ethics advisor network. The purpose of the network was to ensure that every discipline had an academic member of staff as a research ethics advisor to undertake support, which included providing judgement-free and discipline-relevant advice to researchers, delivering ethics workshops relevant to their discipline, participating in the expedited review system, and facilitating communication to and from the ethics committee. Two years after the intervention was implemented, a comprehensive external review found 'universally strong endorsement' for the university's research ethics system which was described as 'effective and responsive' (Allen, 2008, p. 113). It would appear, therefore, that critical researchers wanting more out of their ethics committees have a responsibility to demand that their institutions provide the resources that ethics committees need to enable them to deliver appropriate and optimal support (Pearce, 2002).

\section{Accommodating Participatory Research in Ethics Review}

In most countries, all research with human participants must undergo ethics review, and this includes community-based participatory research. However, practitioners of community-based participatory research have reported an ambiguous positioning of these methods as 'research' in countries including Aotearoa/New Zealand (Marlowe \& Tolich, 2015), Canada (van den Hoonaard, 2002), and the United States (Malone, Yerger, McGruder, \& Froelicher, 2006). Conservative notions about what does and does not constitute scientific inquiry means that practitioners of community-based participatory research are not always clear about when ethics approval to conduct 'research' is or is not required. Researchers report being excluded from ethical review processes even when they were conducting health and disability research that clearly should have been eligible for ethics review (Marlowe \& Tolich, 2015), and this seems particularly likely when the people conducting research are not employed by a university nor collaborating with academics. In these instances, opportunities to obtain ethics guidance are missed, and this is unfortunate given the kinds of ethics issues to which community-based participatory research gives rise.

Practitioners of community-engaged participatory research have highlighted the difficulties of drafting a detailed research proposal for ethics review prior to the commencement of research. This is largely because community-engaged 
participatory research is a form of emergent inquiry in which the research process is shaped by an iterative interchange among research questions, data collection, and analysis (e.g., Cockburn \& Cundill, Section 1). Attempts should still be made to describe the intended process as fully as possible. For Wassenaar and Mamotte (2012), the difficulty in describing emergent forms of inquiry for ethics review 'is not a sound reason for not persisting in finding a way of doing it. Researchers should address ethical issues in their research with the same intellectual and creative vigour that they use to develop methodologies and analytic methods' (p. 273).

There are many issues that ethics committees might assist communitybased participatory research practitioners to consider before entering the field. Critical researchers may appreciate feedback about ways of involving communities in defining what constitutes ethical research. Some members of ethics committees might be ideally placed to offer advice about the kinds of interpersonal skills needed to foster and maintain community collaboration, develop trust and transparency, and how to respond in the event that this is compromised. Ethics committees might also be ideally placed to advise about the importance of negotiating mutually agreed-upon aims and objectives in participatory research and how to develop and implement methods that enhance democratic engagement (see, e.g., Lovell \& Akhurst, Section 4). Likewise, critical researchers may wish for advice about attending to power differentials in the community and negotiating how communities and individual members will be represented, for example when considering naming willing participants (see, e.g., Ashdown et al., Section 3). Negotiating a clear understanding of who has ownership of the 'data' is also a potentially predictable issue or one about which an ethics committee might offer advice when it arises unexpectedly (see, e.g., Mayeza, Section 4).

Persistent engagement in ethics considerations in community-based participatory research is important. Tatebe (2015) argues that the necessity to 'get through' (p. 233) the ethics review and approval process places greater emphasis on ethics as a static process over conducting ethical research. According to Tolich (2016), this is possibly because ethics committees ask only three questions - 'what is the research about, what are the ethical issues raised by that research, and how will the researcher address those issues?'- when they should ask a fourth as well: 'how will the researcher address the ethical issues that arise in the field that neither the researcher nor the ethics committee can predict during ethics review?' (pp. 46-47). Thus, ethics committees supportive of community-based participatory research and all critical research could help researchers to think through the kinds of issues that may arise in the process of the research and to put in place appropriate support mechanisms. 


\section{Conclusion}

For every ethical imperative that is constructed within health and social fields of research, critical research as a collective presents challenges and critical researchers face challenges that resonate personally. In sharing stories of these challenges, the authors of chapters in this handbook have demonstrated ways of traversing ethical imperatives that exist in the dominant forms of ethics review across the many varied international contexts. The tools of narrative and reflexivity prove powerful in deconstructing ethical imperatives and reenvisioning a future for critical research subjects to a more inclusive and responsive process of ethics review.

This chapter has concluded the handbook with a re-analysis of four overarching issues across the sections of the handbook: (1) learning how to apply process ethics in critical research through researcher education, communities of practice, and researcher reflexivity; (2) constructions of vulnerability in critical research that apply both to potential participants and researchers; (3) seeking social justice through participation in critical research; and (4) reimagining ethics review by considering the limitations and possibilities of ethics committees in reviewing research applying critical methodologies and epistemologies. In combination with the richness of the worked examples of critical research in each of the chapters, these overarching issues provide recommendations and questions for critical researchers to take forward as we engage in ethical, transformative health and social research.

\section{Notes}

1. See the main introduction chapter for more background on principlism.

\section{References}

Allen, G. (2008). Getting beyond form filling: The role of institutional governance in human research ethics. Journal of Academic Ethics, 6(2), 105-116. https://doi. org/10.1007/s10805-008-9057-9

Ashcroft, R., \& Pfeffer, N. (2001). Ethics behind closed doors: Do research ethics committees need secrecy? British Medical Journal, 322(7297), 1294-1296. Retrieved from http://www.bmj.com/content/322/7297/1294.long

Bond, T. (2012). Ethical imperialism or ethical mindfulness? Rethinking ethical review for social sciences. Research Ethics, 8(2), 97-112. https://doi.org/10.1177/ 1747016112445419 
Brinkmann, S., \& Kvale, S. (2017). Ethics in qualitative psychological research. In C. Willig \& W. Stainton-Rogers (Eds.), The Sage handbook of qualitative research in psychology (2nd ed., pp. 259-273).

Caligiuri, M., Allen, K., Buscher, N., Denney, L., Gates, C., Kantelo, K., ... Fontanesi, J. (2017). A multisite study of performance drivers among institutional review boards. Journal of Clinical and Translational Science, 1(3), 192-197. https:// doi.org/10.1017/cts.2017.8

Carter, B. (2009). Tick box for child? The ethical positioning of children as vulnerable, researchers as barbarians and reviewers as overly cautious. International Journal of Nursing Studies, 46(6), 858-864. https://doi.org/10.1016/j.ijnurstu. 2009.01.003

Cloke, P., Cooke, P., Cursons, J., Milbourne, P., \& Widdowfield, R. (2000). Ethics, reflexivity and research: Encounters with homeless people. Ethics, Place \& Environment, 3(2), 133-154. https://doi.org/10.1080/713665889

Cooke, B., \& Kothari, U. (2001). Participation: The new tyranny? London: Zed Books.

Cornwall, A. (2003). Whose voices? Whose choices? Reflections on gender and participatory development. World Development, 31(8), 1325-1342. https://doi. org/10.1016/S0305-750X(03)00086-X

Cornwall, A., \& Brock, K. (2005). What do buzzwords do for development policy? A critical look at 'participation', 'empowerment' and 'poverty reduction'. Third World Quarterly, 26(7), 1043-1060. https://doi.org/10.1080/014365905002 35603

de Jong, J. P., van Zwieten, M. C., \& Willems, D. L. (2013). Research monitoring by US medical institutions to protect human subjects: Compliance or quality improvement? Journal of Medical Ethics, 5(2), 159-172. https://doi.org/10.1136/ medethics-2011-100434

de Ville, K., \& Hassler, G. (2001). Healthcare ethics committees and the law: Uneasy but inevitable bedfellows. Healthcare Ethics Committee Forum, 13(1), 13-31.

de Vries, R., \& Forsberg, C. P. (2002). Who decides? A look at ethics committee membership. Healthcare Ethics Committee Forum, 14(3), 252-258.

Etherington, K. (2007). Ethical research in reflexive relationships. Qualitative Inquiry, 13(5), 599-616. https://doi.org/10.1177/1077800407301175

Fitzgerald, M. H., Phillips, P. A., \& Yule, E. (2006). The research ethics review process and ethics review narratives. Ethics \& Behavior, 16(4), 377-395. https://doi. org/10.1207/s15327019eb1604_7

Gallant, D. R., \& Bliss, A. (2006). Qualitative social science research. In E. A. Bankert \& R. J. Amdur (Eds.), Institutional review board: Management and function (2nd ed., pp. 397-401).

Guta, A., Nixon, S., Gahagan, J., \& Fielden, S. (2012). "Walking along beside the researcher": How Canadian REBs/IRBs are responding to the needs of communitybased participatory research. Journal of Empirical Research on Human Research Ethics, 7(1), 17-27. 
Guta, A., Nixon, S. A., \& Wilson, M. G. (2013). Resisting the seduction of "ethics creep": Using Foucault to surface complexity and contradiction in research ethics review. Social Science \& Medicine, 98(1), 301-310.

Haggerty, K. (2004). Ethics creep: Governing social science research in the name of ethics. Qualitative Sociology, 27, 391-414. https://doi.org/10.1023/B:QUAS. 0000049239.15922.a3

Hale, E. D., Treharne, G. J., \& Kitas, G. D. (2007). Qualitative methodologies I: Asking research questions with reflexive insight. Musculoskeletal Care, 5, 139-147. https://doi.org/10.1002/msc.109

Hammersley, M. (2015). On ethical principles for social research. International Journal of Social Research Methodology, 18(4), 433-449. https://doi.org/10.1080/1 3645579.2014 .924169

Hedgecoe, A. M. (2012). Trust and regulatory organisations: The role of local knowledge and facework in research ethics review. Social Studies of Science, 42(5), 662-683. https://doi.org/10.1177/0306312712446364

Hickey, S., \& Mohan, G. (2004). Participation-From tyranny to transformation? Exploring new approaches to participation in development. London: Zed Books.

Iphofen, R. (Ed.). (2017). Finding common ground-consensus in research ethics across the social sciences (Vol. 1). Bingley: Emerald Group Publishing.

Israel, M., \& Hay, I. (2006). Research ethics for social scientists. London: Sage.

Juritzen, T. I., Grimen, H., \& Heggen, K. (2011). Protecting vulnerable research participants: A Foucault-inspired analysis of ethics committees. Nursing Ethics, 18(5), 640-650. https://doi.org/10.1177/0969733011403807

Kotsis, S. V., \& Chung, K. C. (2014). Institutional review boards: What's old, what's new, what needs to change? Plastic and Reconstructive Surgery, 133(2), 439-445.

Louw, B., \& Delport, R. (2006). Contextual challenges in South Africa: The role of a research ethics committee. Journal of Academic Ethics, 4(1-4), 39-60.

Lyons, A. C., \& Chamberlain, K. (2006). Health psychology: A critical introduction. Cambridge: Cambridge University Press.

Lyons, A. C., \& Chamberlain, K. (2017). Critical health psychology. In B. Gough (Ed.), The Palgrave handbook of critical social psychology (pp. 533-555). London: Palgrave Macmillan.

Malone, R. E., Yerger, V. B., McGruder, C., \& Froelicher, E. (2006). 'It's like Tuskegee in reverse': A case study of ethical tensions in institutional review board review of community-based participatory research. American Journal of Public Health, 96(11), 1914-1919. https://doi.org/10.2105/AJPH.2005.082172

Marlowe, J., \& Tolich, M. (2015). Shifting from research governance to research ethics: A novel paradigm for ethical review in community-based research. Research Ethics, 11(4), 178-191.

McKenzie-Mohr, S., \& Lafrance, M. (2011). Telling stories without the words: 'Tightrope talk' in women's accounts of coming to live well after rape or depression. Feminism \& Psychology, 21(1), 49-73. https://doi.org/10.1177/0959353 510371367 
Mistry, J., Berardi, A., \& Simpson, M. (2009). Critical reflections on practice: The changing roles of three physical geographers carrying out research in a developing country. Area, 41(1), 82-93. https://doi.org/10.1111/j.1475-4762.2008.00841.x

Murray, M. (Ed.). (2014a). Critical health psychology (2nd ed.). London: Palgrave Macmillan.

Murray, M. (2014b). Social history of health psychology: Context and textbooks. Health Psychology Review, 8(2), 215-237. https://doi.org/10.1177/13591053 17705879

Murray, M., \& Chamberlain, K. P. (2014). Health psychology. In T. Teo (Ed.), Encyclopedia of critical psychology (pp. 844-850). New York: Springer.

O'Neill, J. (2010). One chairperson's experience of ethical review: Balancing principle, convention, relationship and risk in educational research. International Journal of Research \& Method in Education, 33(3), 229-243. https://doi.org/10.1080/174 3727X.2010.511715

Ogden, J. (2012). Health psychology (5th ed.). London: Open University Press.

Pearce, M. (2002). Challenging the system: Rethinking ethics review of social research in Britain's National Health Service. In W. C. van den Hoonaard (Ed.), Walking the tightrope: Ethical issues for qualitative researchers (pp. 43-58). Toronto: University of Toronto Press.

Pittaway, E., Bartolomei, L., \& Hugman, R. (2010). 'Stop stealing our stories': The ethics of research with vulnerable groups. Journal of Human Rights Practice, 2(2), 229-251. https://doi.org/10.1093/jhuman/huq004

Queen's University Belfast. (2017). Introduction to ethics. Retrieved September 21, 2017, from http://www.qub.ac.uk/Research/Governance-ethics-and-integrity/ Ethics/

Quigley, D., Sonnenfeld, D., Brown, P., Silka, L., He, L., \& Tian, Q. (2016). Research ethics training on place-based communities and cultural groups. Journal of Environmental Studies and Sciences, 6(3), 479-489. https://doi.org/10.1007/ s13412-015-0236-x

Reubi, D. (2010). The will to modernize: A genealogy of biomedical research ethics in Singapore. International Political Sociology, 4, 142-158. https://doi.org/10. $1177 / 0306312712439457$

Rhodes University. (2017). Ethical standards committee. Retrieved September 21, 2017, from http://ruconnected.ru.ac.za/course/view.php?id=5399

Richardson, S., \& McMullan, M. (2007). Research ethics in the UK: What can sociology learn from health? Sociology, 41(6), 1115-1132. https://doi.org/10.1177/ 0038038507082318

Smith, L. J. (2008). How ethical is ethical research? Recruiting marginalized, vulnerable groups into health services research. Journal of Advanced Nursing, 62(2), 248-257. https://doi.org/10.1111/j.1365-2648.2007.04567.x

Stark, L. (2012). Behind closed doors: IRBs and the making of ethical research. Chicago: University Of Chicago Press. 
Steele, L. M., Mulhearn, T. J., Medeiros, K. E., Watts, L. L., Connelly, S., \& Mumford, M. D. (2016). How do we know what works? A review and critique of current practices in ethics training evaluation. Accountability in Research, 23(6), 319-350. https://doi.org/10.1080/08989621.2016.1186547

Stewart-Withers, R. (2016). Edge walking ethics. New Zealand Sociology, 31(4), 28-42. Retrieved from https://search.proquest.com/docview/1852699623

Swartz, S. (2011). 'Going deep' and 'giving back': Strategies for exceeding ethical expectations when researching amongst vulnerable youth. Qualitative Research, 11(1), 47-68. https://doi.org/10.1177/1468794110385885

Tatebe, J. (2015). The ethics of difference: Ethical dilemmas of external researchers. Journal of Academic Ethics, 13(3), 229-237. https://doi.org/10.1007/s10805015-9236-4

Tolich, M. (2016). A narrative account of ethics committees and their codes. New Zealand Sociology, 31(4), 43-55. Retrieved from https://search.proquest.com/ docview/1852699744

Tolich, M., Bathurst, R., Deckert, A., Flanagan, P., Gremillion, H., \& Grimshaw, M. (2016). One size does not fit all: Organisational diversity in New Zealand tertiary sector ethics committees. Kötuitui: New Zealand Journal of Social Sciences Online, 11(1), 23-35. https://doi.org/10.1080/1177083X.2015.1035732

Twine, R. (2005). Constructing critical bioethics by deconstructing culture/nature dualism. Medicine, Health Care and Philosophy, 8(3), 285-295. https://doi. org/10.1007/s11019-004-7812-2

University of Waikato. (2017). Human research ethics committee. Retrieved September 21, 2017, from http://www.waikato.ac.nz/research-enterprise/ethics/humanethics-research-committee

van den Hoonaard, W. C. (Ed.). (2002). Walking the tightrope: Ethical issues for qualitative researchers. Toronto: University of Toronto Press.

van den Hoonaard, W. C. (2011). The seduction of ethics: Transforming the social sciences. Toronto: University of Toronto Press.

van den Hoonaard, W. C., \& Hamilton, A. (Eds.). (2016). The ethics rupture: Exploring alternatives to formal research-ethics review. Toronto: University of Toronto Press.

Wassenaar, D. R., \& Mamotte, N. (2012). Ethical issues and ethics reviews in social science research. In M. M. Leach, M. J. Stevens, G. Lindsay, A. Ferrero, \& Y. Korkut (Eds.), The Oxford handbook of international psychological ethics (pp. 268-282). Oxford: Oxford University Press.

Whiteman, N. (2017). Accounting for ethics: Towards a de-humanised comparative approach. Qualitative Research. https://doi.org/10.1177/1468794117724499

Wilkinson, S., \& Kitzinger, C. (2013). Representing our own experience: Issues in "insider" research. Psychology of Women Quarterly, 37(2), 251-255. https://doi. org/10.1177/0361684313483111 